\title{
A opção pela docência e os aprendizados da prática profissional: percursos formativos de estudantes participantes do Pibid em Minas Gerais $^{1}$
}

\author{
Lorene dos Santos ${ }^{2}$ \\ Andreia dos Santos ${ }^{3}$
}

\begin{abstract}
Resumo
Este texto enfoca os percursos formativos de estudantes participantes do Programa Institucional de Bolsa de Iniciação à Docência (Pibid), em cinco IES de Minas Gerais. São apresentados e discutidos dados quantitativos levantados por meio de um questionário eletrônico que contemplou aspectos relativos ao perfil socioeconômico dos bolsistas, seu percurso formativo e suas percepções sobre a licenciatura e a experiência de formação proporcionada pelo Pibid. Os dados quantitativos são cotejados com dados do Censo do Ensino Superior (2013 e 2014), e as respostas à questão aberta do questionário são analisadas a partir de aportes da pesquisa qualitativa, em diálogo com referenciais teóricos do campo da formação docente. Os resultados trazem evidências de alguns dos aprendizados realizados, dos confrontos e dos desafios enfrentados, além das perspectivas de ingresso e permanência na profissão.
\end{abstract}

Palavras-chave: formação inicial de professores; percursos formativos; Pibid.

$1 \mathrm{O}$ presente artigo foi elaborado a partir de uma pesquisa apoiada pelo CNPq.

2 Doutora em Educação. Professora do Programa de Pós-graduação em Educação da PUC Minas. Coordenadora do Pibid História/PUC Minas.

3 Doutora em Sociologia. Docente do Departamento de Ciências Sociais da PUC Minas. Coordenadora de Sociologia do Pibid/PUC Minas. 


\title{
The option for teaching and practical professional learning: the formative paths of students participating in Pibid in Minas Gerais
}

\begin{abstract}
This text focuses on the formative paths of students participating in the Institutional Scholarship Program for Teacher Initiation (Pibid) in five Higher Education Institutions (IES) in Minas Gerais. This work presents and discusses quantitative data collected through an electronic questionnaire that dealt with aspects related to their socioeconomic profile, their formative path and their perceptions about the teaching profession and formative experience provided by Pibid. Quantitative data are compared to the Higher Education Census (2013 and 2014) and the answers to the open question present in the questionnaire are analyzed through a qualitative perspective, in dialogue with theoretical references of the area of teacher education. The results provide evidence of some of what was learnt, of confrontations and challenges that were faced and of the perspectives of entering and remaining in the teaching profession.
\end{abstract}

Keywords: initial teacher formation; formative paths; Pibid.

\section{Introdução}

A formação de professores tem sido tema de debates e emerge como objeto de preocupação dos poderes instituídos, desde os incipientes investimentos em prol da constituição de um sistema público de ensino, ainda no período Imperial. Com o advento da República, e durante as primeiras décadas do século $X X$, cresceu o interesse pela docência e seus processos formadores, passando a englobar também os primeiros investimentos na formação de professores para atuarem no então denominado "Ensino Secundário" (que corresponde, na atualidade, aos anos finais do Ensino Fundamental e Ensino Médio). Observa-se, a partir 
dos anos 1930, a criação dos primeiros cursos regulares e específicos, em que a licenciatura consistia em acrescentar um ano de disciplinas da área da educação à formação de bacharéis, configurando, assim, um modelo que passou a ser conhecido como " $3+1$ ", cujas marcas perduram até os dias atuais (GATTI, 2010).

Adentramos o século XXI em uma condição de formação de professores nas áreas disciplinares em que, mesmo com as orientações mais integradoras quanto à relação "formação disciplinar/formação para a docência", na prática ainda se verifica a prevalência do modelo consagrado no início do século XX para essas licenciaturas. (GATTI, 2010, p. 1357).

Em muitas situações, verificamos que o binômio formação disciplinar/ formação para a docência é traduzido como uma dicotomia na relação teoria/prática, sendo apontado por professores e pesquisadores como um dos importantes desafios a serem enfrentados pelos atuais projetos e políticas de formação docente, como discutiremos adiante.

A primeira metade do século XX é caracterizada pela emergência de um conjunto mais sistematizado de prescrições e um crescente processo de normatização e busca por controle sobre o trabalho dos professores, configurando-se modelos de docência e de um "professor ideal", que se tornam parâmetros para a organização da formação docente.

A formação e o trabalho docente emergiram como objetos de pesquisa somente a partir da segunda metade do século XX, consolidando-se como área de interesse de pesquisadores do campo da educação no início deste século XXI. Segundo mapeamento realizado por André (2009), na última década do século XX, $6 \%$ da produção acadêmica brasileira (dissertações e teses) na área da educação versaram sobre a formação de professores, com foco para a formação inicial. Nos primeiros anos do século XXI, esse percentual mais que dobrou, e o foco dos estudos concentrou-se, predominantemente, em questões relativas à identidade e à profissionalização, prevalecendo o interesse em compreender quem são os docentes e quais os seus saberes. De acordo com André: “Um aspecto muito promissor das pesquisas mais recentes é a atenção dada ao professor. Muitos estudos foram produzidos nos últimos anos, em 
torno das opiniões, das representações, dos processos de constituição de identidade, dos saberes e práticas dos professores" (ANDRÉ, 2009, p. 51).

Os estudos brasileiros seguem a tendência internacional das pesquisas sobre formação e trabalho docente que, segundo Diniz-Pereira (2013), a partir dos anos 2000, também têm como foco o tema das múltiplas identidades docentes, questão que permeia "vários estudos sobre socialização docente e construção do conhecimento dos professores" (DINIZ-PEREIRA, 2013, p. 148).

Além de se expandir como campo de pesquisa, nas últimas décadas, a formação docente também se tornou alvo privilegiado de políticas públicas de educação, observando-se o surgimento desurgimento de uma nova legislação educacional, com destaque para a LDBEN 9.394/96, e96, e de um conjunto de normatizações, como é o caso das Diretrizes Curriculares Nacionais para a Formação de Professores da Educação Básica (2002) $)^{4}$.

Este texto dialoga com o campo de estudos sobre formação docente e com o campo das políticas públicas de educação. Serão apresentados e discutidos os resultados parciais de uma investigação que tem como objeto de estudo os percursos formativos vivenciados por estudantes de licenciatura participantes de uma das recentes políticas de formação inicial de professores implementadas no Brasil: o Programa Institucional de Bolsa de Iniciação à Docência - Pibid. Buscou-se conhecer dimensões do perfil socioeconômico de estudantes de licenciatura de cinco IES mineiras ${ }^{5}$, cotejando os resultados com dados recentemente divulgados pelo Censo da Educação Superior. Além de perscrutar aspectos das múltiplas identidades desses professores em formação, a pesquisa procurou compreender seus percursos formativos, interessandose, particularmente, pelos aprendizados realizados, pelos saberes construídos e pelas perspectivas de ingresso na profissão.

Criado em 2007, o Pibid é um desdobramento das novas atribuições da

\footnotetext{
4 Em 2015, o Conselho Nacional de Educação institui novas Diretrizes Curriculares Nacionais para a Formação Inicial e Continuada em Nível Superior de Profissionais do Magistério para a Educação Básica, por meio da Resolução nº 2, de $1^{\circ}$ de julho de 2015.

$5 \mathrm{O}$ campo de pesquisa foi constituído por três Instituições Federais de Ensino Superior (IFES): UFMG, UFSJ, UNIFAL; uma IES estadual, UEMG; e uma IES privada confessional, PUC Minas.
} 
Coordenação de Aperfeiçoamento de Pessoal de Nível Superior (CAPES), que passou a ser responsável por "induzir e fomentar a formação inicial e continuada de profissionais da educação básica e estimular a valorização do magistério em todos os níveis e modalidades de ensino", a partir da Lei 11.502/07. Entre os diversos objetivos definidos para o Pibid, destacamos dois que se relacionam mais diretamente com a pesquisa aqui apresentada: (a) inserir os licenciandos no cotidiano de escolas da rede pública de educação, proporcionando-lhes oportunidades de criação e de participação em experiências metodológicas, tecnológicas e práticas docentes de caráter inovador e interdisciplinar, que busquem a superação de problemas identificados no processo de ensino-aprendizagem; (b) contribuir para a articulação entre teoria e prática necessária à formação dos docentes, elevando a qualidade das ações acadêmicas nos cursos de licenciatura ${ }^{6}$.

As diretrizes estabelecidas - sobretudo pela aposta na parceria entre instituições de ensino superior e escolas de educação básica - e as condições de financiamento criadas pelo Pibid representam uma novidade na história das políticas públicas de formação docente no Brasil. O Programa é caracterizado por uma relativa autonomia das Instituições de Ensino Superior para elaborarem seus projetos institucionais e os subprojetos de cada área de conhecimento (além de alguns subprojetos interdisciplinares), ampliando as possibilidades de que sejam contempladas as realidades locais e regionais e o atendimento a diferentes demandas de formação. Dados do MEC e um estudo realizado pela Fundação Carlos Chagas (GATTI et al., 2014) apontam que o Pibid vem se configurando como uma política pública de alto impacto na qualidade da formação de docentes para a Educação Básica, tanto pela sua abrangência e capilaridade, quanto pelos resultados que tem logrado ${ }^{7}$. Em levantamento realizado no escopo da pesquisa aqui

\footnotetext{
6 A lista de objetivos e outras informações referentes ao Programa estão disponíveis em: <http:/ / www. capes.gov.br/educacao-basica/capesPIBID>. Acesso em: 20 fev. 2016.

7 Em março de 2014, o Pibid atingiu 90.254 bolsistas, dos quais 72.845 eram de iniciação à docênci, vinculados a 284 Instituições de Ensino Superior distribuídas por todo o território nacional. A partir de junho de 2015, o Programa começou a sofrer cortes e ameaças de redução e/ou reestruturação, justificadas por cortes orçamentários no Ministério da Educação.
} 
apresentada, foram identificados 70 trabalhos sobre o Pibid, incluindo resultados de pesquisas, estudos teóricos e relatos de experiência, publicados entre 2011 e 2015. Uma análise preliminar desses trabalhos revela algumas das potencialidades do Programa, podendo-se identificar a construção de experiências de formação docente multifacetadas e polissêmicas, vividas com diferentes intensidades de envolvimento, compromisso e satisfação por parte dos sujeitos participantes. Prevalece, entre os trabalhos analisados, uma avaliação positiva do Programa. Mesmo com a recente profusão de estudos e publicações, o Pibid ainda apresenta desafios para o campo das pesquisas sobre formação inicial de professores, sendo necessário aprofundar os conhecimentos sobre os processos formativos vivenciados pelos sujeitos, os aprendizados da prática profissional, os saberes construídos, as perspectivas de ingresso e a permanência na profissão. Apostamos também que as pesquisas realizadas junto aos participantes do Programa contribuem para se ampliar a compreensão sobre quem são - potencialmente - os futuros professores brasileiros, interrogando dimensões de sua identidade, seus percursos formativos e suas percepções sobre a escola pública e o papel da educação escolar. Essas são algumas das questões a que nos propusemos investigar.

\section{Diálogos com o campo da formação e trabalho docente}

Nas últimas décadas, novas perspectivas de análise têm configurado uma crescente produção acadêmica sobre formação e trabalho docente, em diferentes países. Muitos dos estudos empreendidos vêm considerando as histórias de vida dos docentes como indissociáveis de suas histórias profissionais, reconhecendo que os modelos de ensino e de professor, internalizados ao longo de sua trajetória como estudante, exercem forte influência na constituição de sua identidade docente (NÓVOA, 1992; GOODSON, 2008).

Tardif (2002) propõe que as pesquisas sobre docência considerem os atores individuais, sua personalidade e suas experiências pessoais e profissionais, que se concretizam na realização de seu trabalho cotidiano, 
assentando-se em "transações constantes entre o que eles são (incluindo as emoções, a cognição, as expectativas, a história pessoal deles, etc.) e o que fazem" (TARDIF, 2002, p. 16). Defende, assim, que as dimensões da identidade dos sujeitos são uma chave fundamental para se compreender a dinâmica, a evolução e as características da atividade docente, o que deve ser feito em diálogo com as próprias situações de trabalho relatadas pelos professores.

Dentro dessa perspectiva, partilhada por tantos outros estudiosos, tem crescido o interesse em compreender o que fazem e o que pensam os professores, os saberes construídos e mobilizados em sua lida cotidiana e a própria natureza de seu trabalho, que inclui uma dimensão eminentemente prática, o que demandaria aprofundar os conhecimentos sobre o que tem sido denominado de "epistemologia da prática". Longe de ser local de "aplicação" de saberes produzidos em outros espaços e por sujeitos alheios ao processo - tal como prevalece em uma lógica de "racionalidade técnica" - a prática profissional docente seleciona, mobiliza, recria e constrói novos saberes, em função das exigências do trabalho e em operações complexas e situacionais (TARDIF, 2002). Assim, o saber dos professores só pode "ser compreendido em íntima relação com o trabalho deles na escola e na sala de aula", posto que "o saber está a serviço do trabalho", é mediado pelo trabalho, produzido e modelado no e pelo trabalho (TARDIF, 2002, p. 16).

Bernstein (1996) nos convida a pensar sobre a relação que o professor estabelece com os saberes que ensina como uma relação criativa, caracterizada por certo grau de autonomia em relação às diferentes instâncias prescritivas que atravessam a educação escolar, em processos que obedecem a "um princípio recontextualizador que, seletivamente, apropria, recoloca, refocaliza e relaciona outros discursos, para construir sua própria ordem e seus próprios ordenamentos" (BERNSTEIN, 1996, p. 259).

A questão dos saberes e das práticas docentes também tem sido abordada pela ótica da relação teoria-prática. Considerando a complexidade dessa relação, Roldão (2007) nos lembra que alguns dos dilemas aí envolvidos remetem à própria gênese histórica da profissão, 
em que a atividade de ensinar antecede a formalização de um conjunto de conhecimentos sistematizados em torno do ensino. A autora ressalta que tal situação é característica de atividades sociopráticas, como a medicina e o ensino.

Consideramos que a clássica fórmula relação teoria-prática transporta uma conceptualização simbólica que pode ser pouco operativa, ocultando a íntima dependência de um campo diante do outro. De facto, tal formulação vem sendo apropriada no sentido de uma visão destes dois campos como entidades separadas no seu desenvolvimento, cuja interligação se traduziria apenas em processos de aplicação - da teoria à prática. É essa leitura aplicacionista que se evidencia como dominante entre os docentes, tal como a investigação nos dá conta. (ROLDÃO, 2007, p. 98).

Ao abordar os saberes construídos por licenciandos participantes do Pibid, esta pesquisa se deparou com alguns dos dilemas envolvidos na "relação teoria-prática", tema que compareceu em diversos depoimentos, como se verá posteriormente neste texto.

A ênfase nas categorias saberes e práticas docentes (TARDIF, 2002; TARDIF; LESSARD, 2005; NUNES, 2001; LELLIS, 2001), ou sua abordagem pela perspectiva da relação teoria-prática, tem orientado estudos e balizado o movimento de reformas educacionais em curso a partir dos anos 1990, que têm como importante alvo a formação docente.

Shulman (2001) nos lembra que as reformas educacionais das últimas décadas têm se preocupado em estabelecer uma "base de conhecimentos" para o ensino, compreendida como "um conjunto codificado ou codificável de conhecimentos, destrezas, compreensão e tecnologia, de ética e disposição, de responsabilidade coletiva, e também um meio para representá-la e divulgá-la"; e pergunta: "Quais são as fontes da base de conhecimento para a docência? Em que termos se pode conceituar essas fontes? Quais são os processos de ação e raciocínios pedagógicos e quais as suas implicações para as políticas de formação docente?" (SHULMAN, 2001, p. 168) . $^{8}$

Buscando obter subsídios para responder tais questões, Shulman e

8 Tradução livre de trechos do texto "Conocimiento y enseñanza", de Lee Shulman, em sua versão em espanhol. 
sua equipe têm observado grupos de professores, desde sua formação inicial, passando pelo ingresso na carreira, até os primeiros anos de docência, investigando "como se acrescentam os conhecimentos de pedagogia e das matérias na mente dos jovens professores". De acordo com o autor, "o tropeço dos novatos se converte em uma janela para a investigação", e as "observações revelam e sublinham os complexos acervos de conhecimentos e destrezas necessários para desempenhar com eficácia a docência" (SHULMAN, 2001, p. 169).

As contribuições de Shulman são pertinentes para a pesquisa que desenvolvemos, na medida em que alguns dos dilemas e dificuldades expressos pelos estudantes pesquisados - ou alguns de seus "tropeços" - explicitam a complexidade dos percursos formativos e trazem importantes pistas sobre os aprendizados da prática profissional, podendo-se converter em "janela" para o avanço das pesquisas e de políticas de iniciação à docência, como é o caso do Pibid.

Shulman elenca quatro principais fontes de conhecimento para o ensino, sendo a última delas "a sabedoria que advém da própria prática” (SHULMAN, 2001, p. 175), considerada extremamente ampla e a menos codificada de todas. Daí que um dos maiores desafios das investigações em educação "consiste em recolher, cotejar e interpretar os conhecimentos práticos dos professores, para criar uma bibliografia de casos e começar a codificar os saberes oriundos da prática, identificando seus princípios, precedentes e parábolas" (SHULMAN, 2001, p. 181), o que demanda trabalho conjunto entre pesquisadores e educadores.

Segundo Shulman, os professores possuem extensa bagagem de conhecimentos que sequer tentam sistematizar. Por isso, nos diz o autor:

Uma das maiores frustrações da docência como fazer e profissão é o esquecimento individual e coletivo de práticas bem sucedidas, em que as melhores criações de quem se dedica a profissão se perdem e não se tornam acessíveis para os atuais e futuros profissionais. (SHULMAN, 2001, p. 180).

Inspirados em Shulman, podemos dizer que a produção de pesquisas e de relatos de experiência sobre o Pibid tem contribuído para o "não esquecimento" de práticas bem-sucedidas. Na medida em que o 
programa potencializa os intercâmbios e as parcerias entre universidades e escolas de educação básica, favorecendo a sistematização e a divulgação de experiências exitosas - seja pela elaboração de relatórios, seja pela apresentação de trabalhos em eventos acadêmicos e publicação de textos em diferentes veículos de divulgação - ele pode estar contribuindo para "recolher, cotejar e interpretar os conhecimentos práticos dos professores, para criar uma bibliografia de casos e começar a codificar os saberes oriundos da prática", como propõe Shulman (2001).

Reconhecendo o Pibid como campo privilegiado para realizar estudos dessa natureza, a presente pesquisa se propõe a escutar os professores em formação, interrogando as percepções desses sujeitos sobre as experiências vivenciadas, os aprendizados realizados, os saberes e as práticas construídos, e em que medida esses processos os aproximam ou os distanciam da escolha pela docência.

\section{Caracterização do campo de pesquisa e aportes metodológicos}

O universo desta pesquisa foi composto por 884 estudantes, bolsistas do Pibid vinculados a cinco IES mineiras ${ }^{9}$. Como se pode observar no gráfico a seguir, o maior percentual de participantes foi do curso de Pedagogia (17,5\%), seguido pelo curso de Ciências Biológicas, com $10,9 \%$. O menor percentual foi do curso de Dança, com apenas 1,2\% do total de participantes.

9 Do total de 884 respondentes, 32\% eram estudantes da PUC Minas; 20\%, da UEMG; $18 \%$, da UFSJ; $15 \%$, da UFMG; e outros $13 \%$, da UNIFAL. 


\section{Gráfico 1 - Distribuição de bolsistas por curso, nas cinco IES}

\section{Distribuição de bolsistas por curso, nas cinco IES (\%)}

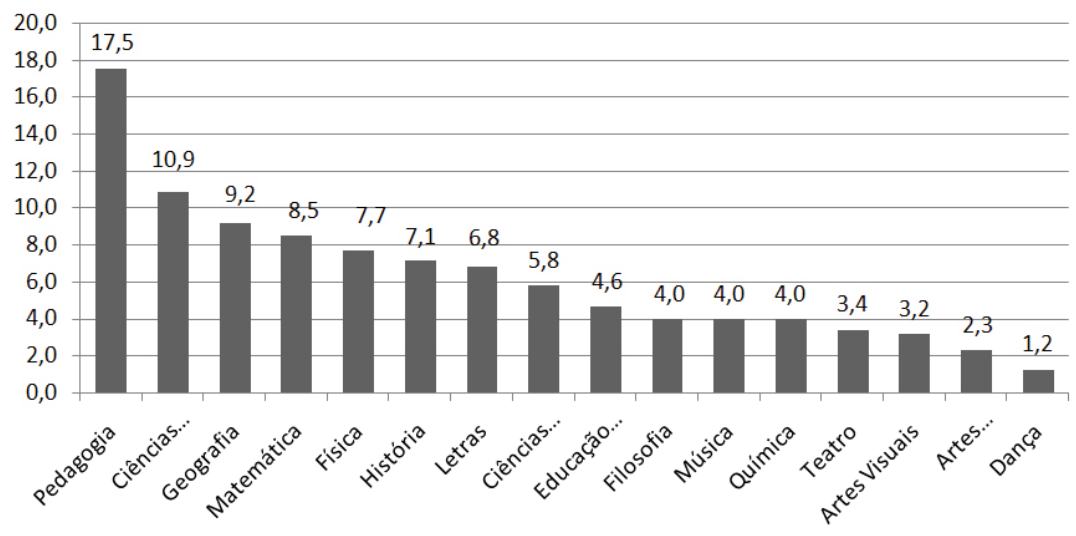

Fonte: Dados da pesquisa

A maioria dos estudantes atuava como bolsista de iniciação à docência do Pibid no momento de aplicação do questionário eletrônico, e um percentual reduzido era recém-egresso do Programa ${ }^{10}$. O número de bolsistas pesquisados correspondeu a pouco mais de $10 \%$ do total de bolsistas de iniciação à docência em Minas Gerais, levando-se em consideração dados oficiais do Programa, de 2014.

Ao selecionar cinco IES - quatro públicas e uma privada - entre as 37 participantes do Pibid em Minas Gerais, não houve a pretensão de que os dados obtidos pudessem ser generalizados para todas as IES mineiras, tampouco para outras universidades brasileiras. Apostou-se, no entanto, que muitos dos saberes, das práticas e das percepções expressas pelos sujeitos participantes do Pibid nessas instituições fossem partilhadas por inúmeros outros professores em formação, em diferentes contextos

10 Os questionários foram aplicados entre agosto e dezembro de 2015. Para viabilizar a participação do maior número de bolsistas, a aplicação foi realizada presencialmente, durante os horários de encontros de bolsistas nas IES pesquisadas, em laboratórios de informática e por meio do uso de tablets. Todos os bolsistas foram convidados a participarem, mas a participação foi voluntária. Os questionários eram anônimos, mas houve controle dos respondentes, que assinaram o "Termo de Consentimento Livre e Esclarecido", conforme estabelecido pelo Comitê de Ética em Pesquisa. A aplicação presencial permitiu um alcance significativo de participantes. 
educativos. Partimos do pressuposto de que o foco em alguns contextos específicos permite realizar um estudo em profundidade e construir chaves interpretativas, contribuindo para o avanço do conhecimento, por meio da elaboração de modelos explicativos não generalizáveis, mas que podem servir de referência para a análise de outras situações e contextos (ALVES-MAZOTTI, 2001).

A investigação aqui proposta pode ser caracterizada como uma pesquisa quali-quanti, uma vez que opera com grande número de dados quantitativos, gerados por meio da aplicação de questionário eletrônico, ao mesmo tempo em que propõe análises pautadas pelos pressupostos e fundamentos da pesquisa qualitativa, em que a "ênfase recai sobre a compreensão das intenções e do significado dos atos humanos" (ALVESMAZZOTTI, 2001, p. 146).

André (2007) compara a produção acadêmica em educação do início dos anos 1990 e do início dos anos 2000, e aposta em uma crescente aceitação dos estudos quantitativos, identificando o uso mais frequente do questionário como técnica de coleta. Diniz-Pereira (2013), ao discutir a construção do campo de pesquisa sobre formação de professores, em âmbito internacional, cita a ponderação feita pelo pesquisador norteamericano Kenneth Zeichner, sobre a necessidade de maior investimento em pesquisas que combinem análises quantitativas e qualitativas.

A presente pesquisa assume esse desafio, apresentando análises de dados quantitativos e qualitativos. Os dados quantitativos permitiram traçar o perfil socioeconômico dos estudantes pesquisados, buscando-se conhecer e problematizar dimensões de sua identidade. Os resultados encontrados foram cotejados com dados apresentados pelo Censo da Educação Superior $(2013$; 2014).

A fonte dos dados foi um questionário eletrônico composto de 76 questões fechadas e de duas questões abertas, sendo estas últimas de preenchimento opcional. Entre os 884 participantes, 290 responderam a uma das questões abertas, que se destinavam a comentários e/ou observações livres sobre o PIBID ou sobre o próprio questionário, cujas respostas são objeto de análise neste texto. Foram também selecionadas para a análise algumas questões fechadas que dizem respeito às 
dimensões da identidade e ao perfil socioeconômico dos sujeitos, assim como seu percurso de formação no Ensino Médio e no Pibid, buscandose conhecer quem são os estudantes que vêm optando pela profissão docente e quais fatores contribuem para essa escolha.

\section{Quem são os bolsistas do Pibid nas instituições estudadas?}

Dados do Censo da Educação Superior (INEP; 2014) apontam que o número de matrículas nesse nível de ensino superou 7,8 milhões de alunos em 2014, sendo registrado um aumento de $96,5 \%$, entre os anos de 2003 e 2014. As instituições privadas têm participação de 74,9\% do total de matrículas de graduação, contra $25,1 \%$ de matrículas em instituições públicas. Os cursos de licenciatura correspondem a 18,7\% do total de matrículas no Ensino Superior, em 2014, com 1.466.635 estudantes, entre os quais $58,8 \%$ estudam em instituições privadas, e $41,2 \%$, em instituições públicas.

No universo investigado, há a predominância de estudantes do sexo feminino (67\%), em relação ao sexo masculino (32\%), em sintonia com dados divulgados pelo Censo da Educação Superior (INEP; 2013) sobre a prevalência das mulheres no Ensino Superior, sobretudo nas Licenciaturas, em que elas totalizam 72,2\% dos estudantes no Brasil. Os números também se coadunam com dados históricos sobre o perfil profissional do magistério, em que as mulheres tornaram-se maioria desde o final do século XIX (VILLELA, 2000). Além das opções "homem” e "mulher", o questionário usado na pesquisa apresentou as opções "homem trans", "mulher trans", "não binário" e "outros", sendo que seis respondentes $(0,67 \%$ do total) se declararam como "não binário", e apenas um informou ser "homem trans". Embora esses dados possam ser estatisticamente inexpressivos, vale acompanhar as manifestações de alguns estudantes, por meio da questão aberta, sobre a importância de se investigar e de se considerar a diversidade das dimensões de identidade de gênero e sexualidade em instrumentos dessa natureza: 
Parabenizo o questionário por incluir várias opções de gênero e orientação sexual, pois como uma pessoa transgênero, ter minha identidade de gênero contemplada não é só respeitador mas também importante para dar visibilidade à minha comunidade. (Bolsista ID UFSJ, 2015).

Este questionário foi claro e objetivo. Foi muito bom poder observar a preocupação com a questão do gênero e sexualidade, mas em alguns momentos faltou a flexibilização textual de gênero. (Bolsista ID UNIFAL, 2015).

Em relação à orientação afetiva sexual, 82\% dos estudantes marcaram a opção heterossexual; 6,3\% , a opção homossexual; e 7,1\% se identificaram como bissexuais.

A inserção de questões relativas a diferentes dimensões da identidade dos sujeitos, tais como orientação sexual, identidade religiosa, identidade étnico-racial, práticas culturais e de leitura, entre outras contempladas no questionário, fundamenta-se no pressuposto de que se deve considerar as experiências pessoais dos sujeitos, suas emoções, suas expectativas e sua história pessoal, reconhecendo as constantes transações entre o que são e o que fazem (TARDIF, 2002), uma vez que "não é possível separar o eu pessoal do eu profissional” (NÓVOA, 1992).

Assim, outra importante dimensão investigada diz respeito à identificação étnico-racial dos estudantes. Nessa questão, foram apresentadas as mesmas opções contempladas no questionário do Censo Demográfico Brasileiro, com acréscimo da opção "negro", que foi escolhida por $12,3 \%$ dos respondentes, percentual bem superior aos que se identificaram como "preto" (3,3\%). A opção "pardo" foi a escolhida por $34,7 \%$ dos respondentes, enquanto a opção "branco" alcançou o percentual de 43,1\%. Somando-se os percentuais de estudantes que marcaram as opções " preto", "negro" ou "pardo", alcançamos um total de $50,3 \%$ de sujeitos que poderiam ser identificados como "população negra"11. Esse percentual se aproximou do resultado do Censo Demográfico 2010, em que a soma dos que se autodeclararam "preto"

11 De acordo com o Estatuto da Igualdade Racial, Lei n ${ }^{\circ} 12.288 / 2010$, art. $1^{\circ}$, parágrafo único, considera-se "IV - população negra: o conjunto de pessoas que se autodeclaram pretas e pardas, conforme o quesito cor ou raça usado pela Fundação Instituto Brasileiro de Geografia e Estatística (IBGE)". 
ou "pardo" alcançou um total de 50,7\% da população brasileira, contra $47,7 \%$ que se autodeclarou "branco".

Observa-se maior discrepância entre os resultados alcançados na pesquisa e aqueles disponibilizados pelo Censo da Educação Superior (INEP, 2013), a partir de dados do ENADE, em que 58\% dos estudantes universitários se autodeclararam brancos, contra $8 \%$ de negros e 31\% de pardos/mulatos ${ }^{12}$ (SOARES, 2015). Essa significativa diferença entre os resultados do Censo da Educação Superior - abrangendo todos os graduandos - e os resultados da pesquisa aqui apresentados envolvendo apenas licenciandos - nos instiga a perguntar: o percentual de estudantes negros seria maior nos cursos de licenciatura do que em outras graduações? A participação em um programa como o Pibid poderia ser um elemento favorecedor do processo de reconhecimento e de afirmação da identidade negra por parte desses estudantes? Em que medida uma formação de professores que contemple temas relacionados à diversidade e à educação das relações étnico-raciais pode contribuir para essa afirmação?

Não temos evidências suficientes para responder a todas essas questões, mas a pesquisa mostrou que 314 estudantes (35,5\% do total de respondentes) assinalaram a temática "Educação das relações étnicoraciais" como um dos temas propostos em atividades de formação organizadas pela coordenação do Pibid em sua IES. Essa temática também foi proposta como objeto de estudo nas escolas públicas parceiras, por meio das equipes de bolsistas do Pibid, de acordo com 277 estudantes (31,3\%). A temática "Cidadania e participação política" também é reconhecida como tema de formação e de estudos nas escolas parceiras por $26 \%$ dos estudantes investigados. Podemos fazer inferências sobre como o estudo e a organização de atividades pedagógicas voltadas ao trabalho com a diversidade cultural e a cidadania poderiam contribuir para a afirmação da identidade negra entre os estudantes bolsistas do Pibid, como preconiza a atual legislação educacional brasileira,

$12 \mathrm{O}$ "Questionário do Estudante" do ENADE apresenta uma classificação um pouco diferente daquela do Censo Demográfico, com as seguintes opções: branco(a); negro(a); pardo(a)/mulato(a); amarelo(a) (de origem oriental); indígena ou de origem indígena. Disponível em: <http://portal.inep.gov.br/ enade/questionario-do-estudante>. 
especialmente as leis 10.639/03 e 11.645/08.

Em relação à idade, a faixa etária que tem o maior percentual de estudantes participantes do Pibid nas cinco IES é entre 22-25 anos de idade $(36,3 \%)$, seguida dos alunos que estão na faixa etária entre 1721 anos (32\% dos respondentes), o que indica que mais de $68 \%$ dos estudantes de licenciatura participantes do Pibid são jovens com idade entre 17 e 25 anos. Apenas 5,9\% dos estudantes indicaram ter mais de 38 anos de idade. Dados do ENADE 2005, apresentados por Gatti (2010), indicam um percentual de $46,5 \%$ de estudantes com idade até 24 anos cursando licenciaturas.

Quando inquiridos sobre o período que estavam cursando quando ingressaram no Pibid, 54,2\% indicaram que estavam entre o $1^{\circ}$ e $3^{\circ}$ períodos. Esse dado evidencia uma efetiva alteração do status da formação profissional, com rompimento do modelo 3+1, conforme discutido por Gatti (2010). Se, até então, a inserção dos licenciandos no cotidiano da escola se realizava somente a partir da segunda metade do curso, quando se iniciavam os Estágios Curriculares Obrigatórios, essa inserção vem sendo antecipada por meio do Pibid, fato reconhecido pelos estudantes como aspecto positivo, inclusive por favorecer o amadurecimento quanto à escolha pelo magistério ao longo do curso.

Sobre o percurso de formação no Ensino Médio, cerca de 80\% dos bolsistas do Pibid o cursaram integralmente em escolas públicas, sendo $68,8 \%$, em escolas públicas estaduais. 30\% dos estudantes provêm de famílias com renda de até 2 salários mínimos, e 49\%, de famílias com renda entre dois e cinco salários mínimos. Tais dados indicam que um significativo percentual de futuros professores são oriundos de camadas sociais desfavorecidas. Para $54,2 \%$ dos estudantes, a bolsa do Pibid é a única fonte de renda individual; e, dos 39,8\% que indicaram possuir algum outro tipo de renda, prevalece a renda individual de apenas um salário mínimo (81\% deles).

\section{A opção pela docência e os aprendizados da prática profissional: o que dizem os estudantes}

Algumas das questões propostas aos estudantes permitiram 
identificar os fatores que mais contribuíram para a escolha da profissão docente, a influência exercida por familiares ou outros professores conhecidos, os principais atrativos da profissão, na percepção desses jovens licenciandos, e quais as suas perspectivas quanto ao ingresso e à permanência no magistério.

Sobre o momento de escolha pelo curso de licenciatura, $82 \%$ dos respondentes indicou que isso ocorreu antes de seu ingresso na Universidade. Em relação aos fatores que contribuíram para essa opção profissional ou sobre os elementos que parecem atrair os jovens licenciandos para a docência, as respostas mais assinaladas foram, em primeiro lugar, "Por gostar de dar aulas" (190 respostas); em segundo lugar, "Por influência de outros professores" (135 respostas); e, em terceiro lugar, devido à "Maior chance de conseguir emprego" (60 respostas). Pretendeu-se investigar a possível influência de familiares professores na escolha dos jovens licenciandos. Ao serem questionados sobre a existência de professores na família, 33\% dos estudantes disseram que não, enquanto outros $67 \%$ apontaram que a docência é exercida por familiares, como tios ou primos (40\%), pai e/ ou mãe $(13 \%)$, irmãos (8\%) e outros (6\%). Embora seja expressiva a porcentagem de estudantes que indicam a existência de professores em sua família, apenas $24 \%$ reconhecem que esses parentes professores influenciaram ou contribuíram muito ou medianamente para sua escolha pela docência; já 13\% acreditam ter havido pouca influência, e 20\% afirmam que essa situação em nada influenciou sua escolha pela docência. Compartilhando as ideias de alguns autores (NÓVOA, 1992; TARDIF, 2002) sobre a importância das histórias de vida e das trajetórias familiar e de formação na identidade profissional, julgamos que uma investigação mais criteriosa sobre a influência - favorável ou desfavorável - de familiares professores na escolha pela docência demanda o uso de outros instrumentos e/ ou metodologias capazes de fazer emergir dimensões das trajetórias e dos percursos formativos que não puderam ser averiguados com os instrumentos disponíveis.

A questão aberta do questionário, destinada ao registro de percepções, opiniões, relatos e manifestações espontâneas de diversas naturezas, 
permitiu que os estudantes expressassem livremente suas ideias e avaliações a respeito do Programa e de seus percursos formativos, além de comentários pontuais sobre o próprio instrumento de pesquisa que lhes foi proposto. Algumas respostas trouxeram críticas contundentes à forma de organização do Programa e à atuação de professores e coordenadores, mas a maioria manifestou uma avaliação bastante positiva, acentuando a importância do Pibid para sua formação como docente, para a melhor qualificação dos cursos de licenciatura e também para a melhoria da qualidade do ensino nas escolas da rede pública parceiras. Muitos estudantes usaram esse espaço para manifestar sua gratidão pela oportunidade de participarem do Pibid, ou para agradecerem diretamente aos professores que os acompanharam e às escolas que os acolheram. Muitos outros também manifestaram sua preocupação com o recente anúncio de redução ou de extinção do Programa, ou aproveitaram o espaço para protestar contra o baixo valor da bolsa ou quanto à ausência de auxílio transporte para se deslocarem até as escolas em que atuam ${ }^{13}$.

Entre as críticas apresentadas, destacamos primeiramente aquelas que se voltam aos cursos de licenciatura e a alguns de seus professores, como os relatos dos estudantes, que dizem:

O PIBID é muito importante, mas a Universidade acaba por legitimar o estereótipo de que não vale a pena ser professor, pois a academia oferece pouquíssimos espaços para exposição das atividades do Programa. Nas mostras de profissões e nos congressos de iniciação científica, houve pouca visibilidade para os cursos de Pibid e de licenciatura. (Bolsista ID UFSJ, 2015).

[...] podemos citar que o Programa vai além disto, porque leva o licenciando a elaborar questionamentos para o professor universitário, conduzindo-o a refletir sua prática, no ensino superior, seja sobre os conteúdos ou em sua postura como formador. (Bolsista ID UEMG, 2015).

[...] Acredito também que a qualificação dos professores dos cursos

13 Entre as 290 respostas contabilizadas na questão aberta, encontramos muitos pontos convergentes, que guardam semelhanças entre si. Selecionamos depoimentos que nos pareceram mais eloquentes e capazes de expressarem alguns desses pontos, ressaltando que inúmeras outras respostas poderiam ser objeto de discussão. 
superiores (não bolsista do PIBID) devem ser avaliadas, pois na universidade estamos nos deparando com vários professores do qual deveriam estar contidos em um manual de como não ser professor e isso se torna desanimador e as vezes até um fator para desistência e mudança de curso. Acredito que a CAPES deveria estar mais atenta a isso, principalmente nos cursos superiores, $\mathrm{o}$ cuidado com a educação superior para os cursos de licenciatura deve ser uma prioridade, quem sabe como sugestão inferir em um curso de formação para docentes para formação de licenciados. (Bolsista ID PUC Minas, 2015).

Considerando que um dos objetivos do Programa se volta ao propósito de promover a elevação da qualidade das ações acadêmicas nos cursos de licenciatura, podemos pensar que, de alguma forma, o Pibid tem contribuído para fomentar processos reflexivos que envolvem tanto os professores das licenciaturas quanto os estudantes bolsistas, explicitando a necessidade de alterações na formação profissional.

Também foi possível observar críticas ao Pibid, tanto em relação às suas formas de organização e de implementação, em cada IES, incluindo o descompromisso de alguns bolsistas, quanto em relação aos recursos disponíveis para sua efetivação.

Sou bolsista na disciplina de Artes Plasticas. Temos muita dificuldade de construir processos artísticos com os alunos pela falta de material. Muitas vezes temos que improvisar ou levar o que temos. O PIBID disponibiliza pouco recuso para compra dos materiais. Assim não conseguimos dar continuidade os trabalhos. (Bolsista ID UEMG, 2015).

Falta verba! Não temos dinheiro nem para tirar xerox, não temos câmeras, pendrive disponíveis para armazenamento de arquivos relativos ao PIBID, etc. fora outros fatores. (Bolsista ID UFSJ, 2015).

A assistência financeira oferecida pelo Pibid conta apenas com o valor da bolsa, sem auxilio alimentação ou transporte, o que inviabiliza uma participação mais frequente e intensa nas escolas e aumenta vertiginosamente a chance de desistência por parte do bolsista. É necessário que isso seja revisto e alterado para que se torne um programa mais atraente para estudantes de diversas áreas. (Bolsista ID UFMG, 2015).

Observo que muitos bolsistas do PIBID não tem uma relação de 
seriedade com as obrigações do programa. Muitos faltam reuniões na IES e nas escolas por motivos bobos e fracos, pois colocam outras obrigações em patamar de importância maior que o PIBID. (Bolsista ID UFMG, 2015).

[...] alguns pibidianos não vestem a camisa e veem o programa apenas como um programa de bolsas. [...] Estou no PIBID desde 2012 e já perdi as vezes de quantas vezes fui chamado a atenção por atraso e cumprimento das atividades. Quando na verdade as pessoas que deveriam escutar, nem estavam presentes. (Bolsista ID PUC Minas, 2015).

As articulações entre os conhecimentos aprendidos nas licenciaturas e aqueles que lhes são exigidos na prática profissional foi um dos temas abordados pelos estudantes:

O PIBID auxilia na formação do futuro docente, permitindo ao mesmo atuar no lócus de trabalho, a instituição escolar, e proporcionando uma conversa entre o professor que atua e o futuro docente, fazendo uma reflexão da teoria e prática. (Bolsista ID UEMG, 2015).

[...] me sinto mais preparada para sala de aula, eu consegui sair da teoria e estou vivendo a realidade, não é fácil mas estou aprendendo a lidar com as dificuldades, essa troca de experiência é maravilhosa. [...] (Bolsista ID PUC Minas, 2015).

Estamos vivendo na prática o que a teoria nos mostra, podendo contribuir com os professores que estão atuando e pra nossa formação é de suma importância, é um grande aprendizado. (Bolsista ID UNIFAL, 2015).

Programa de grande importância para minha formação, e tem conseguido realizar uma interação entre o ensino básico e o superior, fazendo com que pesquisas de ensino se tornem praticas, esse pode ser um meio de encontrar a solução para muitos problemas. (Bolsista ID UFSJ, 2015).

A experiência no PIBID foi de extrema relevância pessoal e muito rica, possibilitando a tentativa de costurar teoria e prática, trazendo grande sentido e motivo para o curso de licenciatura em si. (Bolsista ID UFMG, 2015).

Como se pode observar, a relação teoria-prática foi tematizada 
pelos estudantes das cinco IES, evidenciando sua relevância para as discussões sobre a formação docente. Ainda que muitas vezes prevaleça uma visão dicotômica e uma perspectiva aplicacionista - da teoria à prática, conforme discutido por Roldão (2007) - os relatos evidenciam as potencialidades do Programa para a construção de articulações entre saberes construídos em diferentes momentos da trajetória de formação profissional, como têm evidenciado autores que se dedicaram a categorizar os saberes docentes, tais como Tardif (2002) e Shulman (2001), entre outros.

Muitos depoimentos trouxeram referências sobre alguns dos aprendizados que têm sido possibilitados pela participação no Programa e que dizem respeito tanto a aspectos do processo de ensinoaprendizagem no âmbito das salas de aula quanto a processos mais amplos, envolvendo uma compreensão sobre os sentidos e os significados da educação escolar. Considerando que uma das características da formação docente consiste na relevância desse aprendizado, que se dá em situações de prática profissional, compreendem-se algumas das razões que levam os estudantes a ressaltarem o caráter exitoso do Programa e a importância do mesmo para sua formação.

Fazer parte do PIBID transformou a minha visão sobre a educação. Temos a oportunidade de vivenciar o nosso futuro espaço de trabalho e compartilhar conhecimento com os atuais professores da educação básica. Somos provocados constantemente a refletir sobre o nosso papel e a refletir sobre a nossa própria prática, edificando-nos como professores preparados e instruídos para a construção de competências da nossa área do conhecimento, bem como contribuindo para que a educação seja cada vez mais libertadora, inclusiva e democrática. (Bolsista ID PUC Minas, 2015).

O PIBID está sendo um projeto muito enriquecedor para a minha formação acadêmica, me possibilitando o contato com a escola, sala de aula, alunos e toda sua rotina formativa da escola. Este contato, na minha formação acadêmica, gera o rompimento de conceitos já constituídos, que devido a realidade encontrada no espaço escolar é necessário a construção de um outro olhar, uma outra perspectiva para um posicionamento profissional qualificado, 
humanista, que modifique as adversidades existentes na área e criando novos caminhos e possibilidades no desenvolvimento social de cada sujeito. (Bolsista ID UEMG, 2015).

Não tenho duvida que o PIBIB é muito importante para a minha carreira como professora, hoje eu vejo na pratica o que é lecionar, preparar uma aula, um material didático, fazer uma sequencia, corrigir atividades, faço leitura e fichamentos textos que mostra o que passa dentro dos muros da escola, hoje nada disso é teoria na universidade, eu tenho o privilegio de realmente viver a experiência. (Bolsista ID UFMG, 2015).

Acredito que o PIBID seja uma da melhore alternativas para se entrar em contanto com ambiente escolar, pois o mesmo propicia um envolvimento com os desafios destes locais sem que haja um comprometimento no mesmo nível de um professor propriamente dito. Acho que se entrasse em contato com a escola, por meio de designação, por exemplo, o impacto seria muito grande e negativo. A minha experiência no PIBID permitiu entender os meandros que permeiam o caminho da docência aos poucos, de maneira gradual. E certamente ao assumir uma sala carregarei muito do que aprendi e ainda aprenderei em minha experiência como bolsista. (Bolsista ID UFMG, 2015).

Em diversos depoimentos, ao ressaltarem o caráter exitoso do Programa, os estudantes compararam a experiência no Pibid com outras vivenciadas em situação de Estágio Supervisionado, e, de um modo geral, apontaram as fragilidades observadas nesse segundo:

Quando iniciei estágio, me senti totalmente desmotivada com a profissão, pois os professores não se mostravam muito abertos a minha presença nem às minhas ideias. Com o PIBID foi tudo diferente. Temos o nosso espaço na escola. (Bolsista ID UFSJ, 2015).

[...] o programa, ao meu ver, supre o que os estágios obrigatórios da licenciatura não dão conta de fazer, prepara realmente as/os estudantes universitárias/os para a futura profissão e também proporciona que as/os novas/os sujeitos que entraram na universidade nesses últimos tempo permaneçam nela. (Bolsista ID UNIFAL, 2015).

Alguns estudantes ressaltaram a oportunidade de contato com as dificuldades e os desafios da profissão, assim como a possibilidade de 
enfrentamento dos problemas, pela via do trabalho coletivo e do diálogo com a comunidade escolar, como se pode observar no depoimento a seguir:

O PIBID é uma grande contribuição para que tenhamos contatos não apenas com as escolas, mas também com os problemas e dificuldades das escolas, e juntamente com coordenação pedagógica, professores e direção, enfrentar os "problemas" da instituição, juntamente a toda a comunidade escolar. Oportunidades essas que vão muito além do estágio, visto a parceria envolvendo Escola/Universidade, formando profissionais mais preparados para enfrentarem as adversidades do cotidiano. (Bolsista ID UNIFAL, 2015).

Além de confirmarem a importância do Programa para o fortalecimento da escolha pelo magistério, também encontramos depoimentos que reconhecem seu papel no processo de desistência da profissão, favorecendo, assim, o amadurecimento das escolhas profissionais ainda durante a graduação.

O Pibid confirmou minha vontade de ser professor. Sei que depois do Pibid posso atuar com confiança e responsabilidade. (Bolsista ID UNIFAL, 2015).

Não tinha certeza se queria atuar como professora até participar desse projeto. Ele tem contribuído muito para minha formação. (Bolsista ID UFMG, 2015).

O programa possibilita a vivencia no meu campo de interesse de atuação, e mostra os desafios e as recompensas, e nos dá inclusive a possibilidade de saber se é isso mesmo que queremos. (Já vi casos de colegas que saíram da graduação de licenciatura após o PIBID.) No meu caso, ele só serviu para constatar essa vontade. (Bolsista ID PUC Minas, 2015)

Para alguns estudantes, o alcance do Pibid ultrapassa a melhoria da qualidade da formação inicial de professores, sendo tanto fator de permanência do licenciando na universidade quanto um Programa que provoca alterações positivas na educação brasileira e nas escolas em que se realiza. Há, inclusive, relatos de bolsistas que tiveram contato com o Pibid durante o Ensino Médio e que ressaltam a importância dessa 
experiência para a sua decisão de ingressar em um curso de licenciatura.

Quando era aluna na escola básica, tive a oportunidade de ser aluna dos Pibidianos de Matemática e isso foi o gatilho que faltava para minha decisão pela docência. (Bolsistas ID UFSJ, 2015).

[...] é também o momento de praticar aquilo que aprendemos no decorrer do curso, além de contribuir para a melhora e o aprimoramento das aulas escolares dos professores supervisores, com elaboração de aulas inovadoras e criação de projetos pedagógicos que acabam beneficiando a própria escola, ao mesmo tempo que aprendemos com os professores também. (Bolsista ID PUC Minas, 2015).

O PIBID é de extrema importância para nossa formação como professores e para os professores já licenciados, além de abrir espaço para nossos supervisores que valorizam nosso trabalho e podem abertamente discutir conosco melhorias para nossa educação. [...] O futuro da educação começa aqui. O investimento começa aqui. (Bolsistas ID UFSJ, 2015).

O pibid é um programa com três vias de benefício: ao corpo discente integrante, ao professor e aos alunos de escolas públicas. A perda do programa acarreta decaimento significativo de qualidade nas aulas e no aprendizado dos alunos de rede publica, além do que a remuneração garante a permanência de muitos discentes no ensino superior, a perda da mesmo poderia implicar um aumento significativo de desistência no curso superior. (Bolsistas ID UNIFAL, 2015).

Por fim, vale ressaltar alguns dilemas e apreensões relatados pelos bolsistas quanto à continuidade dessa política pública e também quanto ao seu futuro profissional, reconhecendo que a perspectiva de entrada e de permanência no magistério também está atrelada às necessárias alterações das condições do trabalho docente e de melhoria da qualidade da educação brasileira, de maneira geral.

É notável os impactos do PIBID em minha formação, entretanto, os cortes na educação somadas a realidade da educação pública brasileira me deixa particularmente insegura quanto a minha futura profissão. Às vezes tenho a impressão de que nos esforçamos tanto, pensamos em soluções para a educação, mas ao mesmo tempo, o governo tenta nos impedir, e pior, nos atrapalhar (por meio dos 
cortes e desvalorização social e monetária da profissão), causando assim uma completa desmotivação, desânimo e desinteresse pela profissão. (Bolsista ID PUC Minas, 2015).

[...] Tal prática, uma das poucas de incentivo à docência, não pode ser marginalizada e inclusive ameaçada de extinção, estamos trabalhando por um bem social, o único capaz de garantir o futuro da nação, lutamos pela educação e não só pela bolsa. É inegável que necessitamos dela para arcar com os custos de nossa formação. Mas o Brasil também precisa ser formado, o Brasil precisa de bases fortes para se manter de pé e só a educação oferece esse alicerce. Portanto, mais do que um programa de bolsas, esse é um programa de vidas, um programa de profissionais, um programa pro futuro. (Bolsista ID UFSJ, 2015).

\section{Considerações finais}

Esta pesquisa possibilitou ouvir estudantes de licenciatura de cinco IES mineiras, buscando favorecer a compreensão de seus percursos formativos. Para o avanço das pesquisas e das políticas públicas de formação docente, faz-se necessário cotejar seus achados e suas descobertas com outros estudos que tiveram objetivo semelhante, a fim de que uma política como essa possa ser discutida de maneira mais qualificada e nuançada pela escuta das vozes daqueles para os quais ela se dirigiu, prioritariamente.

A predominância de avaliações bastante positivas sobre o Pibid nos traz evidências de que se trata de um programa de formação docente bem-sucedido, embora também sinalize para os limites do êxito de uma política pública de incentivo à docência, quando as efetivas condições do trabalho docente não são alteradas. Assim, podemos dizer que os depoimentos dos estudantes reafirmam uma aposta no Programa, a partir de um olhar para a escola de educação básica por parte de quem, em geral, compõe um grupo de recém-egressos dessa mesma escola. Ao dizerem que a escola pública brasileira é viável enquanto projeto de educação transformadora, e que a profissão docente pode ser atraente para as gerações de futuros professores, os estudantes bolsistas do Pibid apontam para uma possível saída da atual crise da educação, que tem como um de seus efeitos mais perversos a ameaça de uma avassaladora 
carência de profissionais dispostos a assumirem o magistério, conforme apontam os índices atuais e os prognósticos para o futuro da profissão. Ao mesmo tempo, a inserção no cotidiano escolar também expõe os desafios e as dificuldades da profissão, ajudando os jovens licenciandos a ultrapassarem visões romantizadas e a romperem com ideias historicamente associadas à profissão, como aquelas que caracterizam o magistério como um "dom" ou uma "vocação". O grupo de jovens licenciandos pesquisado, predominantemente feminino e oriundo de escolas públicas, que depende de bolsas, estágios e outras fontes de renda para se manter na universidade, parece reafirmar sua disposição e seu desejo de tornar-se professora ou professor. Sabemos, no entanto, que a permanência em uma profissão é resultado de uma série de fatores, em um jogo de pesos e medidas que inclui a satisfação pessoal e as condições efetivas de garantia de sobrevivência e de qualidade de vida e trabalho. Uma geração de professores que tem acesso a uma elevação da qualidade de sua formação pode ser também uma geração mais exigente do ponto de vista profissional e das condições de trabalho. Assim, o Pibid pode ser tanto uma boa porta de entrada para a docência quanto um caminho para outros voos profissionais, caso as condições do trabalho docente não atendam às aspirações e às demandas das gerações que almejam ingressar na profissão. O desafio está posto. Darão conta dele as atuais e futuras políticas públicas em educação e as desgastadas promessas de valorização do magistério?

\section{Referências}

ALVES-MAZOTTI, Alda Judith. Relevância e aplicabilidade da pesquisa em educação. Cadernos de Pesquisa, São Paulo, n. 113, p. 39-50, jul. 2001.

ANDRÉ, Marli Eliza Dalmazo de Afonso. A produção acadêmica sobre formação docente: um estudo comparativo das dissertações e teses dos anos 1990 e 2000. Revista Brasileira de Pesquisa sobre Formação de Professores, São Paulo, v. 1, n. 1, p. 41-56, ago./dez. 2009. 
BERNSTEIN, Basil. A estruturação do discurso pedagógico: classe, códigos e controle. Petrópolis, RJ: Vozes, 1996.

BORGES, Cecília. Saberes docentes: diferentes tipologias e classificações de um campo de pesquisa. Educação \& Sociedade, Campinas, SP, a. 22, n. 74, p. 59-76, abr. 2001.

BRASIL. Resolução CNE/CP no 1, de 18 de fevereiro de 2002. Institui Diretrizes Curriculares Nacionais para a Formação de Professores da Educação Básica, em Nível Superior, Curso de Licenciatura de Graduação Plena. Brasília, DF: MEC, 2002.

BRASIL. Instituto Nacional de Estudos e Pesquisas Educacionais Anísio Teixeira (INEP). Censo da educação superior 2013 - resumo técnico. Brasília, DF: Inep, 2015. Disponível em: <http://download.inep.gov. br/download/superior/censo/2013/resumo_tecnico_censo_educacao_ superior_2013.pdf>.

BRASIL. Instituto Nacional de Estudos e Pesquisas Educacionais Anísio Teixeira (INEP). Censo da Educação Superior 2014 - notas estatísticas. Brasília: Inep, 2015. Disponível em: <http://download.inep.gov.br/ educacao_superior/censo_superior/documentos/2015/notas_sobre_o_ censo_da_educacao_superior_2014.pdf>.

DINIZ-PEREIRA, Júlio Emílio. A construção do campo da pesquisa sobre formação de professores. Revista da FAEEBA - Educação e Contemporaneidade, Salvador, BA, v. 22, n. 40, p. 145-154, jul./dez. 2013.

GATTI, Bernadete A. Formação de Professores no Brasil: características e problemas. Educação e Sociedade, Campinas, SP, v. 31, n. 113, p. 13551379, out./ dez. 2010. Disponível em: <http:// www.cedes.unicamp.br>.

A formação inicial de professores para a Educação Básica: as licenciaturas. Revista USP, São Paulo, n. 100, p. 33-46, dez./jan./ fev. 2013-2014. Disponível em: <http:/ / www.revistas.usp.br/revusp/ article/view/76164>. 
GATTI, Bernadete. A. et al. Um estudo avaliativo do Programa Institucional de Bolsa de Iniciação à Docência (Pibid). São Paulo: FCC/SEP, 2014.

GOODSON, Ivor F. As políticas de currículo e de escolarização: abordagens históricas. Petrópolis, RJ: Vozes, 2008.

LELLIS, Isabel Alice. Do ensino de conteúdos aos saberes do professor: Mudança de idioma pedagógico? Educação \& Sociedade, Campinas, SP, a. 22, n. 74, p. 43-58, abr./2001.

NÓVOA, Antônio (Org.). Vidas de professores. Porto: Porto Editora, 1992.

NUNES, Célia Maria Fernandes. Saberes docentes e formação de professores: um breve panorama da pesquisa brasileira. Educação \& Sociedade, Campinas, SP, a. 22, n. 74, p. 27-42, abr./2001.

ROLDÃO, Maria do Céu. Função docente: natureza e construção do conhecimento profissional. Revista Brasileira de Educação, Rio de Janeiro, v. 12, n. 34, jan./abr. 2007.

SHULMAN, Lee S. Conocimiento y Enseñanza. Estudios Públicos, Santiago, Chile, n. 83, invierno 2001. Disponível em: <http://www. cepchile.cl/dms/lang_1/doc_1573.html>.

SOARES, José Francisco. Instituto Nacional de Estudos e Pesquisas Educacionais Anísio Teixeira (INEP). Acesso e permanência no Ensino Superior. Brasília, DF: INEP, 2015. (Power Point). Disponível em: <http://portal.mec.gov.br/index.php?option=com docman\&view=download\&alias=17199-cne-forum-educacao-superior2015-apresentacao-10-jose-soares\&Itemid=30192>. Acesso em: 31 jul. 2016.

TARDIF, Maurice. Saberes docentes \& formação profissional. Petrópolis, RJ: Vozes, 2002. 
TARDIF, Maurice; LESSARD, Claude. O trabalho docente: elementos para uma teoria da docência como profissão de interações humanas. Petrópolis, RJ: Vozes, 2005.

VILELA, Heloisa. O mestre-escola e a professora. In: FARIA FILHO, Luciano Mendes de et al. 500 anos da Educação no Brasil. Belo Horizonte: Autêntica, 2000. 